\title{
Morphological and Molecular Identification of Entomopathogenic Fungi from Agricultural and Forestry Crops
}

\author{
Gustavo Angel Bich ${ }^{1,2 *}$ (1) \\ María Lorena Castrillo ${ }^{1,2}$ \\ Fernando Luis Kramer ${ }^{1}$ \\ Laura Lidia Villalba ${ }^{1}$ \\ Pedro Darío Zapata ${ }^{1,2}$
}

\begin{abstract}
A promising alternative for insect pest control in agriculture is the use of entomopathogenic fungi. The objectives of this work were to isolate and identify morphologically and molecularly strains of entomopathogenic fungi from crops of agricultural and forestry interest for the development of insect biocontrol technologies in Argentina. Three strains of Beauveria bassiana, and two strains of Metarhizium anisopliae were isolated and morphologically identified. Identity values greater than $99 \%$ with strains of B. bassiana and M. anisopliae were obtained in molecular databases. It was also confirmed by phylogenetic methods that the sequences obtained from these strains were positioned within the clade that contained the sequences of reference of $B$. bassiana and M. anisopliae respectively. These results deepen the knowledge of the mycobiota of Argentinian crops as a basis for the development of biotechnological products in the area of biological control.
\end{abstract}

Keywords: Beauveria, Metarhizium, Microscopy, rDNA, Phylogeny.

\section{INTRODUCTION AND OBJECTIVES}

Agriculture and forestry represent two of the main economic activities in the province of Misiones in northeastern Argentina (Weber, 2005). The main crops of the Province are represented by large extensions of citrus, tobacco (Nicotiana tabacum), yerba mate (Ilex paraguariensis), different vegetables, Pinus elliotti, Pinus taeda, Eucalyptus grandis, among others (Izurieta, 2000). The primary activity in agriculture and forestry is affected by several biological agents that cause a great decrease in the production and quality of crops (Sandoval, 2004).

Traditional agriculture uses large amounts of chemical pesticides to control pests, which can act against the environment, beneficial insects and even human health (Kim et al., 2016). These drawbacks are currently generating a shift towards a sustainable agriculture, with a gradual reduction in the application of synthetic chemical compounds.
Currently, research in the area of sustainable agriculture seeks the development of pesticides using organisms with the natural ability to parasitize and kill plant pests (Folgarait et al., 2011, Erler \& Ozgur, 2015). These organisms are commonly called biological control agents.

Entomopathogenic agents include bacteria, fungi, viruses, nematodes and protozoa, and among the fungi the most studied are microorganisms of the genera Beauveria, Metarhizium and Paecilomyces (De et al., 2014).

In this context, the biotechnological use of entomopathogenic fungi as biocontrol agents is presented as a sustainable alternative to the limited number of available chemical pesticides. The characterizations of strains of entomopathogenic fungi, as well as the knowledge of the biological aspects related to the behavior of these strains against susceptible pests, are prerequisites for effective integrated pest management practices (Figueroa et al., 2007).

${ }^{1}$ Universidad Nacional de Misiones, Instituto de Biotecnología Misiones, Laboratorio de Biotecnología Molecular, Posadas, Misiones, Argentina ${ }^{2}$ Consejo Nacional de Investigaciones Científicas y Técnicas (CONICET), Misiones, Argentina 
Traditional morphological identification of fungi is based on the study of macroscopic and microscopic structures (Shenoy et al., 2007, Piontelli, 2015). Especially, the shape and size of the conidia are the most used traits for the identification of Beauveria and Metarhizium species (Samson et al., 1988; Humber, 2012). However, despite its great utility, this identification commonly presents a limitation in terms of phenotypic plasticity and genetic variability in the traits used to identify species ( $\mathrm{Paz}$ et al., 2011).

In recent years, the breakthrough of molecular techniques, mainly those based on the analysis of DNA by the polymerase chain reaction (PCR), have allowed the development of rapid, accurate and applicable to a large number of samples methodologies for the detection and identification of different fungi (Kindermann et al., 1998; Solé, 2002; Schoch et al., 2012). The ribosomal DNA genes (rDNA) and the internal transcribed spacers (ITS) allow the study of the phylogenetic relationships among several groups of entomopathogenic fungi (White et al., 1990; Driver et al., 2000; Rehner \& Buckley, 2005).

Therefore, to generate greater precision in the identification of fungal isolates and analyze their genetic variability, it is important to compare the results obtained by morphological characterization and molecular techniques (Hibbet et al., 2011). Nevertheless, identification studies of fungi with a biotechnological interest in Argentina are still scarce.

Misiones province is one of the wettest areas of Argentina, it has a subtropical climate without a dry season, with high temperatures, short periods of cold and abundant rainfalls. These climate characteristics and conditions promote the development of a wide variety of plant and fungal species, turning the province of Misiones into one of the most favorable regions for the search and isolation of fungal strains (Massoia et al., 2006). Therefore, the knowledge of the diversity of entomopathogenic fungi from soils and agricultural and forestry crops of interest of the province is fundamental in biodiversity studies and in the bioprospecting and development of possible biological control agents (Punja \& Utkhede, 2003).

Morphological and molecular identification of fungi is considered an essential step in the selection of biocontrol agents (Tigano et al., 1995; Boucias et al., 2000). In this work the objectives proposed were to isolate and identify morphologically and molecularly strains of entomopathogenic fungi from crops of agricultural and forestry interest in the province of Misiones (Argentina).

\section{MATERIALS AND METHODS}

\subsection{Sampling and isolation of entomopathogenic fungi}

Sixty samples of insects with symptoms of being attacked by fungi and adjacent soil samples were collected in crops of yerba mate (I. paraguariensis), pineapple (Ananas comosus), P. elliotti, and E. grandis. Insect samples were collected in paper envelopes, while soil samples were collected in plastic bags; both samples types were labeled and kept at room temperature until they were used in the laboratory. These samplings were collected in the cities of Iguazú $\left(25^{\circ} 41^{\prime} \mathrm{S} 54^{\circ}\right.$ $\left.26^{\prime} \mathrm{W}\right)$, San Ignacio $\left(27^{\circ} 16^{\prime} \mathrm{S} 55^{\circ} 33^{\prime} \mathrm{W}\right)$ and Posadas $\left(27^{\circ}\right.$ $26^{\prime} \mathrm{S} 55^{\circ} 53^{\prime} \mathrm{W}$ ) in the mentioned province.

For the collection of insect samples (with signs of fungal attack), a standardized methodology was followed where the samples were placed in a humid chamber and incubated at 28 $\pm 1^{\circ} \mathrm{C}$ to favor fungal development (Texeira \& Faria, 2010). The bearing conidia from the insect's body were collected and inoculated in plates with agar culture media Potato Dextrose (PDA-Britanialab) and Sabouraud Glucose (Britanialab) and incubated at $28 \pm 1{ }^{\circ} \mathrm{C}$ for 5 to 21 days.

Soil samples were taken following the methodologies previously reported by other authors (Lacey \& Solter, 2012; Schapovaloff et al., 2015). For each sample, five zones were randomly selected and subsamples of the first $10 \mathrm{~cm}$ of soil depth were collected reaching a final total amount of 200g. From these subsamples, three serial dilutions were made with sterile distilled water $\left(10^{-1}\right.$, $10^{-2}$ and $\left.10^{-3}\right)$, and $0.1 \mathrm{~mL}$ of the $10^{-2}$ and $10^{-3}$ dilutions were inoculated onto Petri plates with agarized culture medium. These dilutions were homogeneously dispersed onto the surface of the medium using a sterile Drigalsky spatula. Two different agarized culture media were used: the semi-selective culture medium proposed by Doberski and Tribe (1980) with some modifications (glucose $40 \mathrm{~g} / \mathrm{L}$, peptone $10 \mathrm{~g} / \mathrm{L}$, thiabendazole $0.004 \mathrm{~g} / \mathrm{L}$, chloramphenicol $0.5 \mathrm{~g} / \mathrm{L}$; violet $0.01 \mathrm{~g} / \mathrm{L}$; agar $15 \mathrm{~g} / \mathrm{L}$; distilled water $1 \mathrm{~L} \mathrm{pH} \mathrm{6);} \mathrm{and} \mathrm{the} \mathrm{culture} \mathrm{medium} \mathrm{for} \mathrm{entomopathogenic}$ fungi proposed by Posadas et al. (2012) with some modifications (oatmeal flakes $20 \mathrm{~g} / \mathrm{L}$, hexadecyltrimethylammonium bromide $0.6 \mathrm{~g} / \mathrm{L}$, chloramphenicol $0.5 \mathrm{~g} / \mathrm{L}$, agar $15 \mathrm{~g} / \mathrm{L}$, distilled water $1 \mathrm{~L} \mathrm{pH}$ 6). In all cases, the plates were incubated at $28 \pm 1{ }^{\circ} \mathrm{C}$ for 5 to 14 days.

All procedures of direct inoculation of conidia and dispersion of sterile distilled serial dilutions were carried out in triplicate. The fungal growth was observed periodically in the plates and for the search of possible fungal colonies of interest, microscopic observations were carried out (Humber, 2005). 


\subsection{Morphological identification of entomopathogenic fungi}

For morphological identification of the fungal strains, the macroscopic traits of the colonies were observed first. For each colony characteristics such as the color on its upper and lower side of the plates, shape, surface, edge, consistency and elevation were observed (Samson et al., 1988, Humber, 2005, Kirk et al., 2008, Humber, 2012).

For the morphological identification of the entomopathogenic fungal genera of interest, microscopic observations were also made on the size and arrangement of the hyphae, conidiophores and conidia (Samson et al., 1988, Humber, 2005, 2012). The observations and measurements of reproductive structures were made at 400 and 1000 magnifications with a micrometric eyepiece and microphotographs were taken with a Carl Zeiss optical microscope - model 467065-9902-18VA. To determine the microscopic measurements of the reproductive structures, the mean and standard deviation values were calculated and indicated from 20 to 30 measured structures. After identification, the fungal strains were deposited in the collection of microbial strains of biotechnological interest from the Instituto de Biotecnología Misiones of the Universidad Nacional de Misiones - UNaM (Argentina).

\subsection{Molecular identification of entomopathogenic fungi}

Each fungal isolate was inoculated in liquid medium malt extract $12.7 \mathrm{~g} / \mathrm{L}$ (pH 6, Oxoid), and incubated at $28 \pm 1{ }^{\circ} \mathrm{C}$ in the dark for 5 to 7 days for biomass growth. The DNA was extracted by macerating the mycelium in Tris-EDTA buffer $\mathrm{pH} 8$, containing $1.5 \mathrm{M}$ sodium chloride, $0.1 \mathrm{mg} / \mathrm{mL}$ of proteinase $\mathrm{K}, 10 \mathrm{mM} \beta$-mercaptoethanol and $2 \%$ SDS $(\mathrm{w} / \mathrm{v})$. The nucleic acids were purified using a solution of chloroform: isoamyl alcohol $(24: 1, \mathrm{v} / \mathrm{v})$ and $3 \mathrm{M}$ potassium acetate. The DNA was then precipitated with ethanol, dried at room temperature and rehydrated with DNAse-free water (Biopack) (Bich et al., 2017). DNA integrity was evaluated by $1 \%(\mathrm{w} / \mathrm{v})$ agarose gels electrophoresis stained with Gel Red solution (Biotium, 10000X).

The molecular identification of the fungal strains of interest was carried out by amplifying and sequencing the ITS1-5.8SITS2 region of the rDNA. The ITS1 and ITS4 primers were used (White et al., 1990). The PCR reactions were carried out in a final volume of $20 \mu \mathrm{L}$, containing DNase-free water, Buffer 1X, $2.5 \mathrm{mM}$ magnesium chloride, a set of $200 \mu \mathrm{M}$ dNTPs, 10 pmol of each of the primers, Taq polymerase 0.5 units (InBio, Argentina) and $1 \mu \mathrm{g}$ of the extracted DNA. It was used a thermal cycler Hangzhou Bioer Technology CO (GenePro Thermal Cycler, model TC-E-48D, B-48D). The amplification program include an initial step of denaturation at $94^{\circ} \mathrm{C}$ for 4 min, followed by 35 cycles at $94^{\circ} \mathrm{C}$ for $40 \mathrm{~s}, 53$ ${ }^{\circ} \mathrm{C}$ for $40 \mathrm{~s}, 72^{\circ} \mathrm{C}$ for $40 \mathrm{~s}$ and a final extension at $72{ }^{\circ} \mathrm{C}$ for 10 minutes. The obtained amplicons were evaluated by $2 \%(\mathrm{w} / \mathrm{v})$ agarose gels electrophoresis stained with Gel Red solution (Biotium, 10000X). The sequencing of the amplicons was performed by the sequencing service of MACROGEN, Korea.

The sequences obtained were analyzed and the consensus sequences were generated using the Geneious 9.1.5 program (Kearse et al., 2012) and compared with the sequences hosted in the NCBI (http://www.ncbi.nlm.nih.gov/BLAST) and FungalBarcoding (http://www.fungalbarcoding.org) databases.

Phylogenetic trees were constructed with sequences from the ITS region selected from the NCBI-GenBank database (http://www.ncbi.nlm.nih.gov/genbank/) corresponding to the main species within the genera Beauveria and Metarhizium (Table 1). For the analysis were considered reference sequences, data from published papers or sequences from fungal isolates deposited in reference collections. A sequence of the ITS region from Isaria javanica (accession number Genbank DQ403723) was used to root the trees.

Table 1. Genbank accession numbers of selected ITS sequences.

$\begin{array}{ccc}\text { Species } & \text { Genbank accesión number } & \text { Reference } \\ \text { Beauveria amorpha } & \text { HQ880804 } & \text { Rehner et al., 2011 } \\ \text { B. amorpha } & \text { HQ880805 } & \text { Rehner et al., 2011 } \\ \text { B. amorpha } & \text { HQ880806 } & \text { Rehner et al., 2011 } \\ \text { B. amorpha } & \text { HQ880807 } & \text { Genbank } \\ \text { B. amorpha } & \text { NR_111601 } & \text { Genbank } \\ \text { Beauveria bassiana } & \text { AY531974 } & \text { Rehner \&Buckley, 2005 } \\ \text { B. bassiana } & \text { AY531982 } & \text { Rehner \& Buckley, 2005 } \\ \text { B. bassiana } & \text { AY531993 } & \text { Rehner \& Buckley, 2005 }\end{array}$

Continues... 
Table 1. Continued...

\begin{tabular}{|c|c|c|}
\hline Species & Genbank accesión number & Reference \\
\hline B. bassiana & AY531994 & Rehner \& Buckley, 2005 \\
\hline B. bassiana & AY531996 & Rehner \& Buckley, 2005 \\
\hline B. bassiana & AY531997 & Rehner \& Buckley, 2005 \\
\hline B. bassiana & AY532043 & Rehner \& Buckley, 2005 \\
\hline B. bassiana & AY532044 & Rehner \& Buckley, 2005 \\
\hline B. bassiana & AY532046 & Rehner \& Buckley, 2005 \\
\hline B. bassiana & AY532050 & Rehner \& Buckley, 2005 \\
\hline B. bassiana & AY532054 & Rehner \& Buckley, 2005 \\
\hline B. bassiana & AY532055 & Rehner \& Buckley, 2005 \\
\hline B. bassiana & NR_111594 & Genbank \\
\hline Beauveria brogniartii & KM458156 & Genbank \\
\hline B. brogniartii & KM458157 & Genbank \\
\hline B. brogniartii & KM458160 & Genbank \\
\hline B. brogniartii & KM458164 & Genbank \\
\hline B. brogniartii & KM458165 & Genbank \\
\hline B. brogniartii & KM458166 & Genbank \\
\hline B. brogniartii & KM458167 & Genbank \\
\hline Beauveria caledonica & AY532003 & Rehner et al., 2011 \\
\hline B. caledonica & HQ880819 & Genbank \\
\hline B. caledonica & HQ880820 & Rehner et al., 2011 \\
\hline B. caledonica & KM275469 & Genbank \\
\hline B. caledonica & NR_077147 & Genbank \\
\hline Beauveria pseudobassiana & HQ880793 & Rehner et al., 2011 \\
\hline B. pseudobassiana & HQ880797 & Rehner et al., 2011 \\
\hline B. pseudobassiana & HQ880798 & Genbank \\
\hline B. pseudobassiana & HQ880799 & Rehner et al., 2011 \\
\hline B. pseudobassiana & KT896629 & Genbank \\
\hline B. pseudobassiana & NR_111598 & Genbank \\
\hline Metarhizium album & AF137067 & Driver et al., 2000 \\
\hline M. album & AY375446 & Destéfano et al., 2004 \\
\hline M. album & NR_152950 & Genbank \\
\hline Metarhizium anisopliae & AF137062 & Driver et al., 2000 \\
\hline M. anisopliae & AF137063 & Driver et al., 2000 \\
\hline M. anisopliae & AF137064 & Driver et al., 2000 \\
\hline M. anisopliae & AF516324 & Pantou et al., 2003 \\
\hline M. anisopliae & FJ787313 & Genbank \\
\hline M. anisopliae & AF135211 & Driver et al., 2000 \\
\hline M. anisopliae & AF135212 & Driver et al., 2000 \\
\hline M. anisopliae & AF135215 & Driver et al., 2000 \\
\hline M. anisopliae & AF136376 & Driver et al., 2000 \\
\hline M. anisopliae & AF516287 & Pantou et al., 2003 \\
\hline M. anisopliae & AF516292 & Pantou et al., 2003 \\
\hline M. anisopliae & AF516298 & Pantou et al., 2003 \\
\hline M. anisopliae & AF516301 & Pantou et al., 2003 \\
\hline
\end{tabular}


Table 1. Continued...

\begin{tabular}{|c|c|c|}
\hline Species & Genbank accesión number & Reference \\
\hline M. anisopliae & AF516305 & Pantou et al., 2003 \\
\hline M. anisopliae & AF516309 & Pantou et al., 2003 \\
\hline M. anisopliae & AF516312 & Pantou et al., 2003 \\
\hline M. anisopliae & AF516314 & Pantou et al., 2003 \\
\hline M. anisopliae & AF516317 & Pantou et al., 2003 \\
\hline M. anisopliae & AF516320 & Pantou et al., 2003 \\
\hline M. anisopliae & AF516325 & Pantou et al., 2003 \\
\hline M. anisopliae & AF516313 & Pantou et al., 2003 \\
\hline M. anisopliae & NR_132017 & Genbank \\
\hline M. anisopliae & AF137065 & Driver et al., 2000 \\
\hline M. anisopliae & AF137066 & Driver et al., 2000 \\
\hline Metarhizium flavoviride & AF138267 & Driver et al., 2000 \\
\hline M. flavoviride & AF138268 & Driver et al., 2000 \\
\hline M. flavoviride & AF138269 & Driver et al., 2000 \\
\hline M. flavoviride & AF138272 & Driver et al., 2000 \\
\hline M. flavoviride & AF516291 & Pantou et al., 2003 \\
\hline M. flavoviride & AY375447 & Destéfano et al., 2004 \\
\hline M. flavoviride & NR_131992 & Genbank \\
\hline
\end{tabular}

The sequences of each fungal group were aligned with the Mega version 6 program (Tamura et al., 2013) using the ClustalW tool set with the parameters of creation and extension gaps penalties of 15 and 6.66 respectively.

The constructed trees were analyzed by the statistical methods of Maximum Parsimony (MP), Maximum Likelihood (ML) and Neighbor-Joining (NJ) also with the Mega version 6 program. The statistical support of each of the groups was verified by Bootstrap analysis based on 1000 replications for all cases. The clades with a percentage lower than $50 \%$ were collapsed as a sole group and the consensus phylogenetic trees made by each statistical method were analyzed. The Adobe Photoshop 7 program was used to graphically edit the trees.

\section{RESULTS AND DISCUSSION}

\subsection{Morphological identification of entomopathogenic fungi}

From the samples collected from crops of agricultural and forestry interest, five fungal strains showing typical characteristics of entomopathogenic fungi were isolated. Of these fungi, three strains corresponded to B. bassiana species (coded as HEP 1, HEP 3 and HEP 13) and two strains corresponded to $M$. anisopliae species (coded as HEP 2 and HEP 14).
In the case of fungi of Beauveria genus, the three strains showed white to cream colonies with irregular edges and powdery appearance, typical macroscopic traits of Beauveria genus (Figure 1). The microscopic observations of the three strains presented reproductive structures and conidia with typical morphology, size, and color of B. bassiana species. Strains showed septate mycelium, conidiogenous cells size of 5.4 to 8.7 $\mu \mathrm{m}$ (SD 0.6 to $1.0 \mu \mathrm{m}$ ) $\times 2.0$ to $2.8 \mu \mathrm{m}$ (SD 0.1 to $0.7 \mu \mathrm{m}$ ), with a wide base and a narrowed apex from which multiple chained conidia emerge in a rachis with a zig-zag arrangement. The conidia were hyaline and smooth, with a globose to subglobose structure. The diameters of the conidia showed a mean value of 1.7 to $2.3 \mu \mathrm{m}$ (SD 0.5 to $0.6 \mu \mathrm{m}$ ) (Figure 1).

The remaining two strains of entomopathogenic fungi presented white colonies that after three weeks of incubation developed conidiophores in compact green clusters, typical macroscopic characteristics of Metarhizium (Figure 2). In the microscopic observations, the two strains presented reproductive structures and conidia with morphology, size, and color typical of M. anisopliae. The strains showed septate mycelium and branched conidiophores in the form of a candelabrum, with two or three branches in each septum densely intertwined. Their conidiogenous cells were cylindrical and slightly conical at the apex. Both strains presented conidia of green color and cylindrical shape forming chains aggregated into cylindrical columns. Each cylindrical conidia presented an average length of 4.5 to $5.1 \mu \mathrm{m}$ (SD $0.7 \mu \mathrm{m}$ ) and a width of 2.1 to $2.6 \mu \mathrm{m}$ (SD $0.3 \mu \mathrm{m}$ ) (Figure 2). 


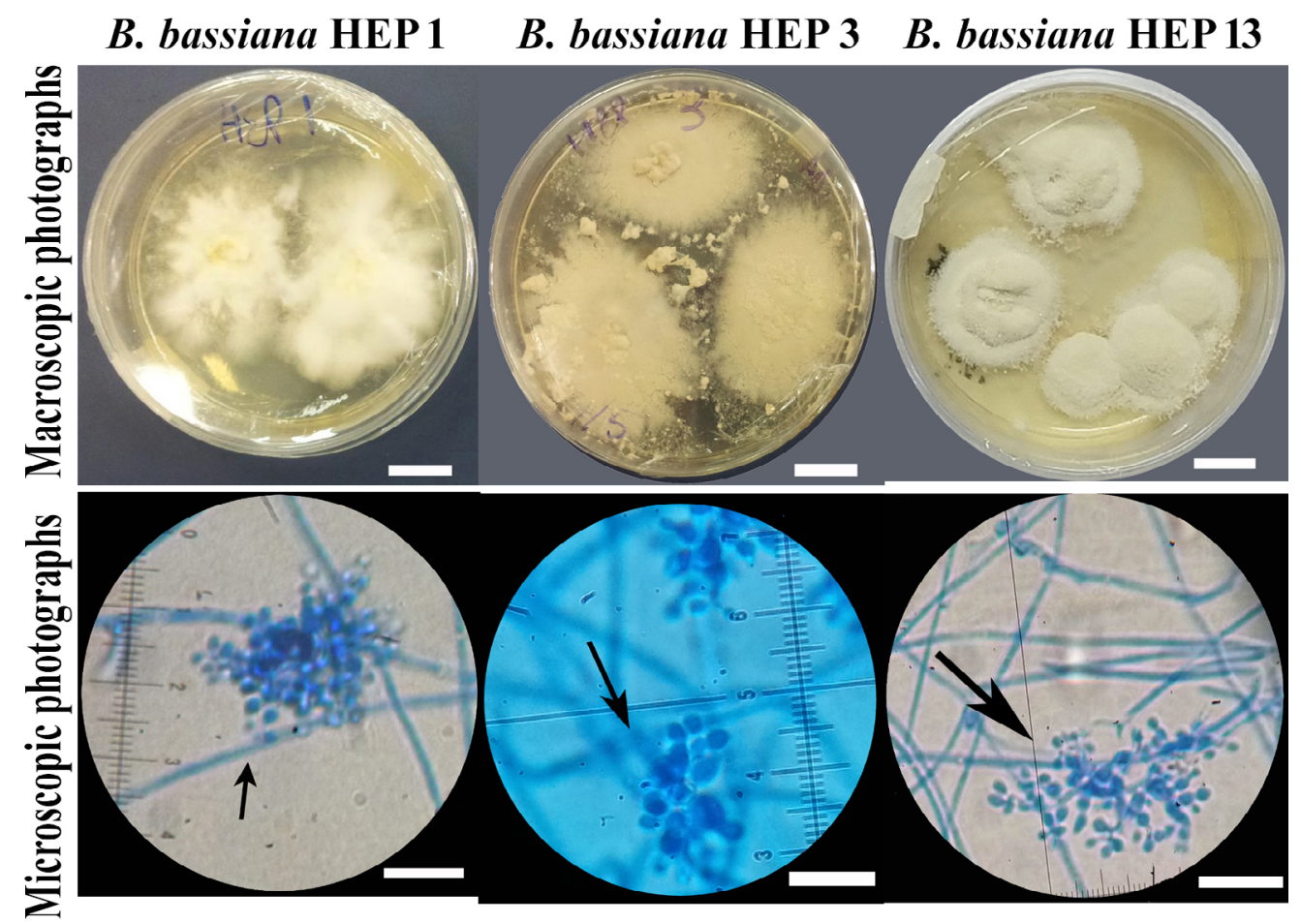

Figure 1. Macroscopic and microscopic photographs of B. bassiana strains. Photographs of colonies in PDA medium $($ Bar $=1 \mathrm{~cm})$. Microphotographs staining with lactophenol blue cotton. The arrow indicates the zigzag arrangement of the conidiogenous cell (Bars $=8 \mu \mathrm{m})$.
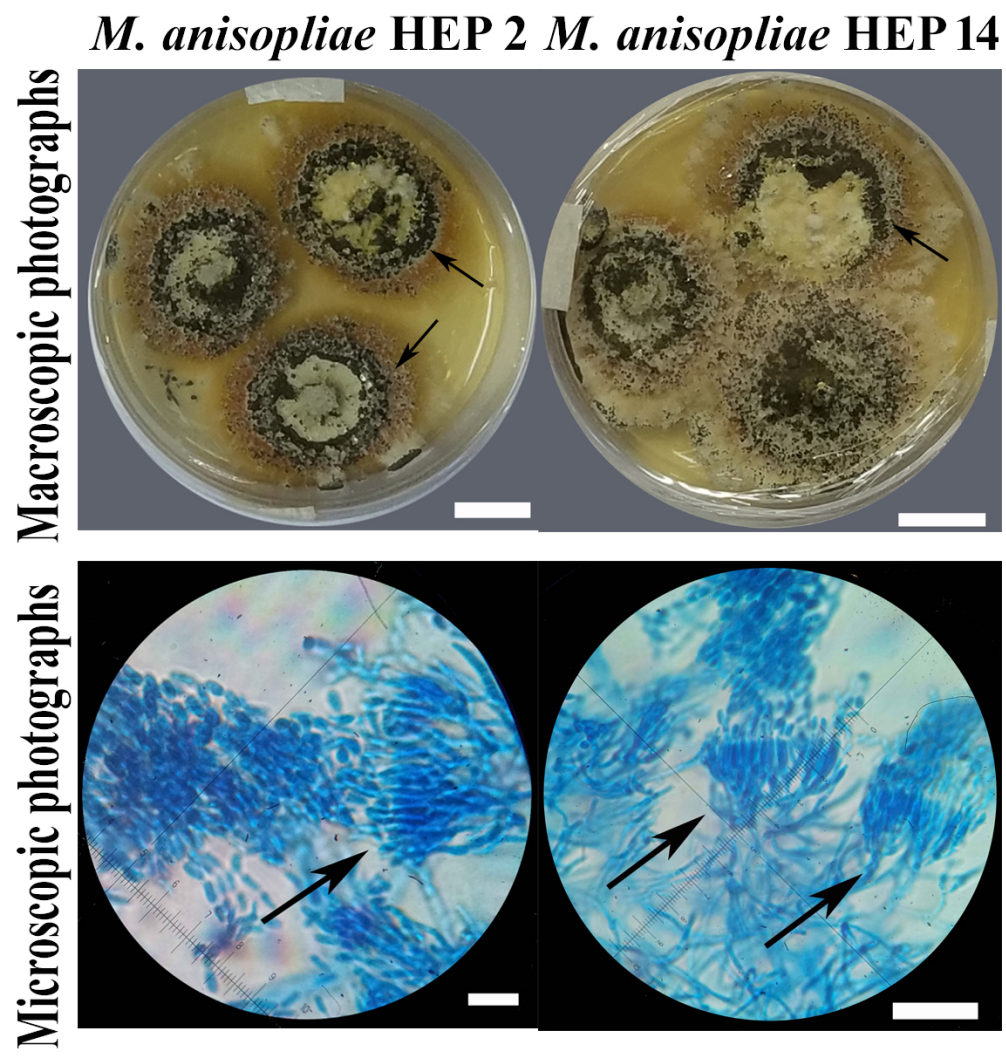

Figure 2. Macroscopic and microscopic photographs of M. anisopliae strains. Photographs of colonies in PDA medium $($ Bar $=1 \mathrm{~cm})$. Microphotographs of samples stained with lactophenol blue cotton. The arrow indicates a group of branched conidiogenic cells $(\mathrm{Bars}=20 \mu \mathrm{m})$. 
The morphological identification (employing macroscopic and microscopic information) allowed the identification of the strains to the genera and species levels. In the present work, the fungal isolations of B. bassiana and M. anisopliae presented similar shapes, sizes and dispositions of conidia with the descriptions made by Samson et al. (1988), Humber (2005, 2012), Kirk et al. (2008) and Rehner et al. (2011).

All the fungal strains obtained corresponded to microorganisms of the Phylum Ascomycota, Sordariomycetes class, and the families Cordycipitaceae for Beauveria, and Clavicipitaceae in the case of Metarhizium (Humber, 2005, 2012).

\subsection{Molecular identification of entomopathogenic fungi}

The PCR products of the ITS regions of the rDNA of the isolated entomopathogenic fungi generated fragments of approximately $600 \mathrm{bp}$.

The results of the identity analysis of the sequences obtained for the three strains HEP 1, HEP 3 and HEP 13 morphologically identified as $B$. bassiana allowed confirming that they belonged to $B$. bassiana species with similarity or identity indexes of $99 \%$. On the other hand, with respect to the fungal strains HEP 2 and HEP 14 morphologically identified as M. anisopliae, similarity or identity indexes of $99 \%$ were obtained with deposited sequences of M. anisopliae. Therefore, it was possible to verify the similarity or identity at the level of DNA sequences for the five isolated strains of entomopathogenic fungi.

To deepen the molecular identification of these isolated strains, the Beauveria and Metarhizium trees of phylogenetic relationships were evaluated in an independent manner.

Analyzing the trees of phylogenetic relationships it was observed that the fungal strains HEP 1, HEP 3 and HEP 13 made a cluster together with fungal strains of $B$. bassiana and with their reference sequence (NR_111594) with Bootstrap values of $98 \%$, for the three methods evaluated (Figure 3 ).

On the other hand, the fungal strains HEP 2 and HEP 14 made a cluster with $M$. anisopliae sequences and its reference sequence (NR_132017) with Bootstrap values of $99 \%$ for the three methods (Figure 4). The phylogenetic analyses provided sufficient information to complement the morphological data obtained and allowed to classify both fungal strains within the $M$. anisopliae species var. anisopliae.

The classical taxonomy employs diverse morphological criteria for the determination of the different fungal genera. Currently, molecular biology techniques are used to identify and characterize the genetic variability of entomopathogenic fungi. The most precise way to determine the levels of diversity and intraspecific genetic structure is through the use of molecular markers (Becerra et al., 2007). Molecular tools are being widely used for the recognition of fungal species, the ITS region of the rDNA is considered the official DNA barcode for fungi since it has hypervariable sequences that allow recognition both at the species level and at lower levels (Schoch et al., 2012; Toju et al., 2012). In the present work, the sequencing of the ITS regions of the rDNA allowed the corroboration of the molecular taxonomic identity of the five fungal strains; and the alignment and phylogenetic analysis confirmed the taxonomic identity of the strains analyzed.

Rehner and Buckley (2005) compared sequences of the ITS1-5,8S-ITS2 region obtained for Beauveria strains and those sequences deposited in the NCBI database, confirming their taxonomic position as belonging to $B$. bassiana. These results are similar to those obtained in the present work since the three strains analyzed were grouped taxonomically as $B$. bassiana with high values of Bootstrap.

Driver et al. (2000) and Pantou et al. (2003) amplifying the ITS1-5,8S-ITS2 region of Metarhizium strains found sufficient genetic variability in these markers to differentiate clades of different species within the genus Metarhizium. In the present work, the genetic variability of the sequenced region allowed us to locate the two native strains of Metarhizium as belonging to the M. anisopliae species var. anisopliae, with topography similar to that reported by Pantou et al. (2003).

It is important to note that molecular techniques do not replace or eliminate the need of use classical morphological taxonomy tools, but instead, they should be used to complement the studies to achieve a complete, accurate and sufficiently descriptive identification (Hyde et al., 2010). Consequently, a procedure of morphological and molecular identification for biocontrol agents is ideal because when applying a biological control system, it is essential a good identification procedure of the fungal isolates that are being used as a way to measure the efficiency of the system (Coates et al., 2002).

The strains of entomopathogenic fungi obtained in the present study will be used later by our working group to evaluate the entomopathogenic capacity against different plague insects of agricultural and forestry crops. The possible application of entomopathogenic fungi in agricultural and forestry crops of Misiones could generate advantages in the health of the crops in a medium and long term, as well as add value to the crops by including techniques of biological management of pests in a sustainable manner. 


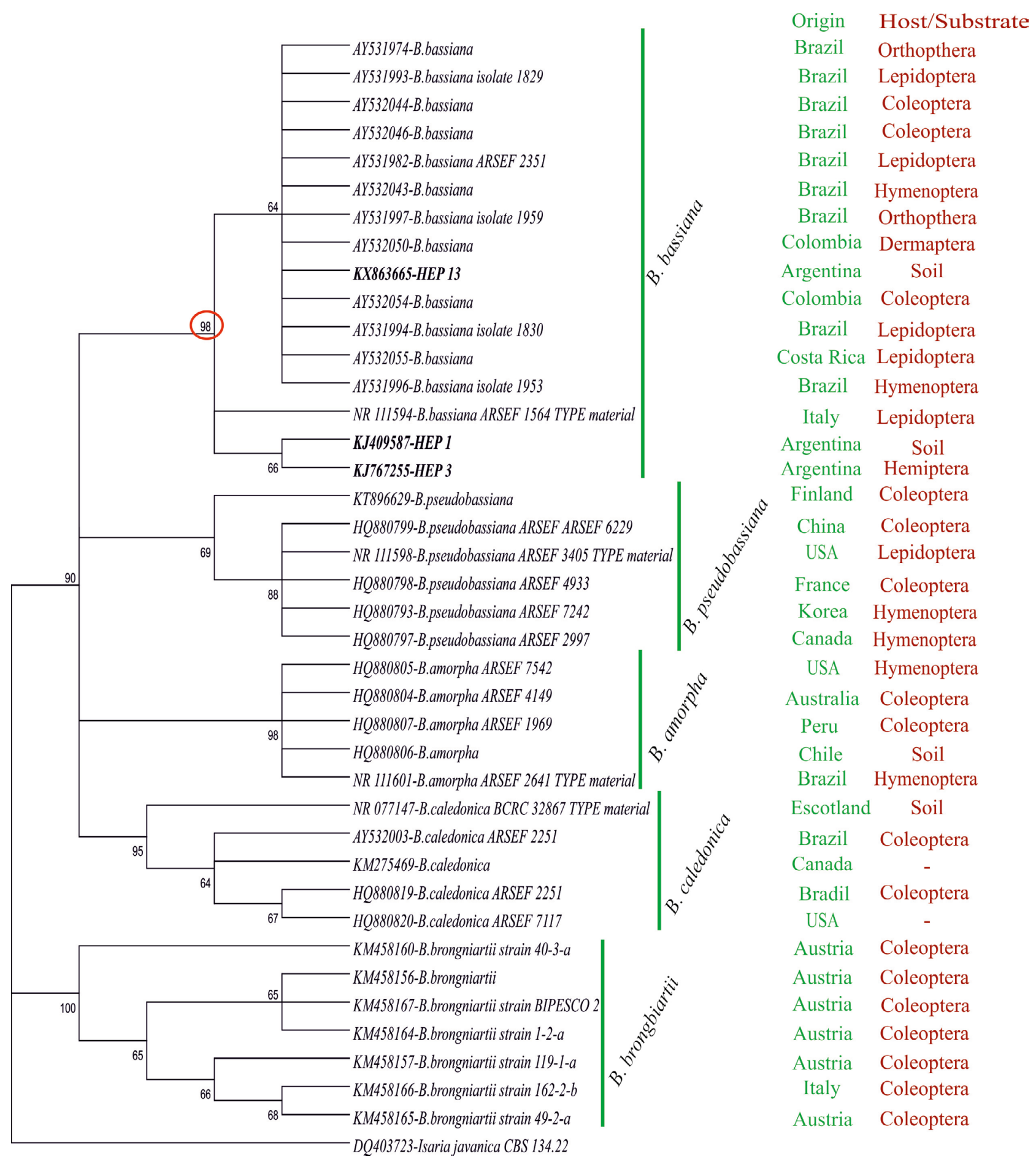

Figure 3. Beauveria consensus tree of phylogenetic relationships. Tree based on the alignment of the ITS1-5.8S-ITS2 region of the rDNA of fungal strains together with sequences obtained from GenBank (NCBI). Bootstrap test with 1000 replications and the Tamura-Nei model for the calculation of genetic distance. The red circle indicates the Bootstrap value obtained for the group of interest. In bold are the entomopathogenic fungi isolated and identified in this work. 


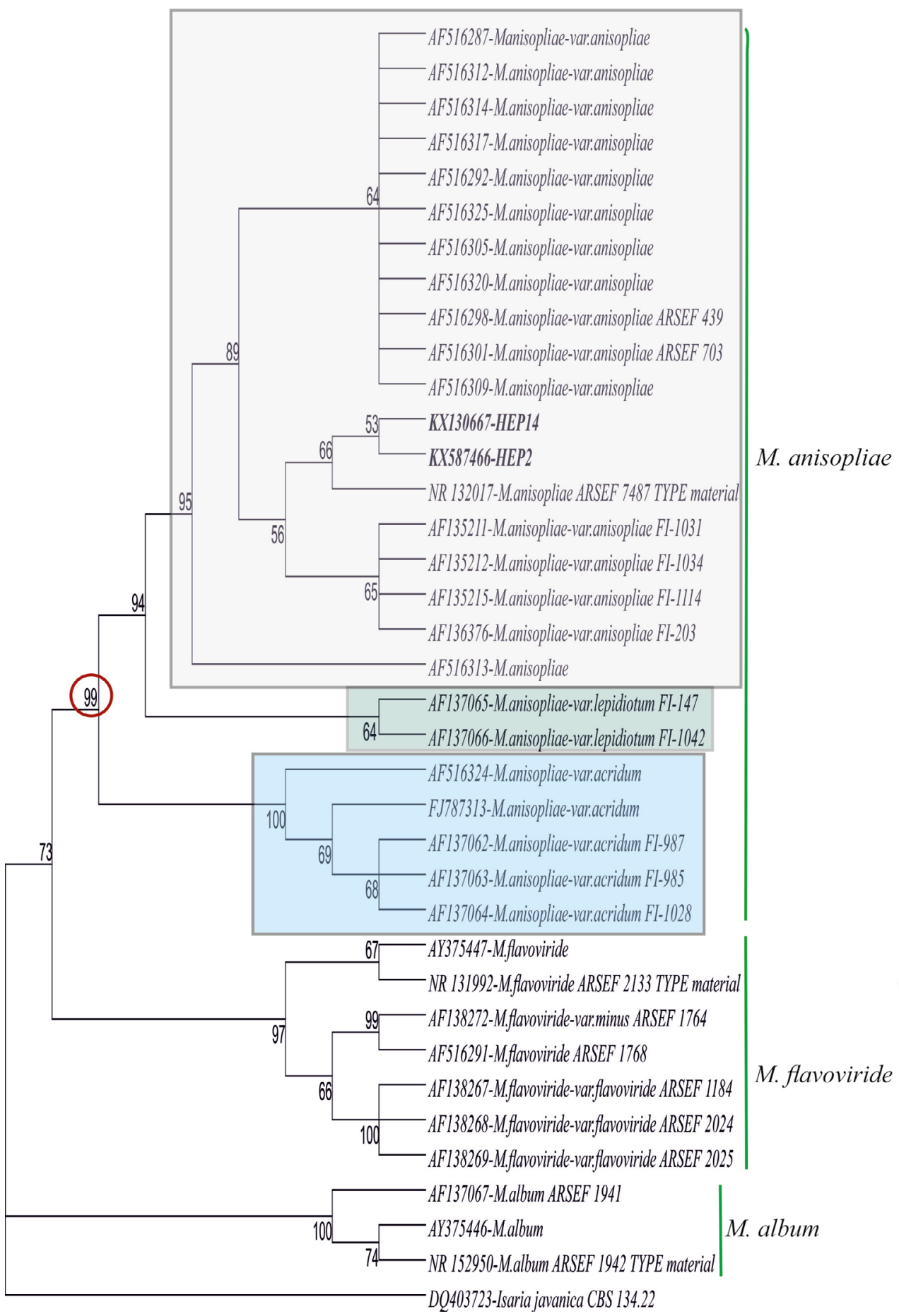

$\begin{array}{cc}\text { Origin } & \text { Host/Substarte } \\ \text { Greece } & - \\ \text { Italy } & \text { Lepidoptera } \\ \text { Austria } & \text { Lepidoptera } \\ \text { Brazil } & \text { Orthoptera } \\ \text { France } & \text { Coleoptera } \\ \text { Austria } & \text { Lepidoptera } \\ \text { Austria } & \text { Coleoptera } \\ \text { Finland } & \text { Soil } \\ \text { Australia } & \text { Orthoptera } \\ \text { China } & \text { Lepidoptera } \\ \text { Denmark } & \text { Soil } \\ \text { Argentina } & \text { Hymenoptera } \\ \text { Argentina } & \text { Soil } \\ \text { Eritrea } & \text { Orthoptera } \\ \text { Oman } & \text { Orthoptera } \\ \text { Tailand } & \text { Orthoptera } \\ \text { Filipines } & \text { Homoptera } \\ \text { Australia } & \text { Soil } \\ \text { Italy } & \text { Homoptera } \\ \text { Fralia } & \text { Hymenoptera } \\ \text { Australia } & \text { Coleoptera } \\ \text { Tustralia } & \text { Coleoptera } \\ \text { Sudand } & \text { Orthoptera } \\ \text { Nigeria } & \text { Orthoptera } \\ \text { Australia } & \text { Orthoptera } \\ \text { Orthoptera } \\ \text { Solomonia }\end{array}$

Figure 4. Metarhizium consensus tree of phylogenetic relationships. Tree based on the alignment of the ITS1-5.8S-ITS2 region of the rDNA of fungal strains together with sequences obtained from GenBank (NCBI). Bootstrap test with 1000 replications and the Tamura-Nei model for the calculation of genetic distance. The red circle indicates the Bootstrap value obtained for the group of interest. In bold are the entomopathogenic fungi isolated and identified in this work. The boxes with different colors show the varieties in the M. anisopliae species. 


\section{CONCLUSIONS}

The present work presents information of entomopathogenic fungi associated with crops of agricultural and forestry interest in the northeast of the Argentine Republic.

Five native strains of entomopathogenic fungi were isolated from the soil samples and parasitized insects. According to their macroscopic and microscopic traits, three strains corresponded to B. bassiana species and two strains corresponded to M. anisopliae species. The amplification and sequencing of the ITS1-5.8S-ITS2 region, the comparison in the molecular databases and the phylogenetic analyses confirmed the taxonomic identity of the strains by molecular techniques.

\section{SUBMISSION STATUS}

Received: 23 Feb. 2018

Accepted: 17 Mar. 2019

Associate editor: João Vicente Latorraca

\section{CORRESPONDENCE TO}

\section{Gustavo Angel Bich}

Universidad Nacional de Misiones, Instituto de Biotecnologia Misiones, Laboratorio de Biotecnologia Molecular, Ruta 12, $\mathrm{Km}$ 7.5, 3300, Misiones, Argentina

e-mail: gustavobich@gmail.com

\section{REFERENCES}

Becerra VV, Paredes C, Rojo CM, France AL. RAPD e ITS detectan variación molecular en poblaciones chilenas de Beauveria bassiana. Agricultura Técnica (Chile), 2007; 67: 115-125.

Bich GA, Castrillo ML, Villalba LL, Zapata PD. Isolation of the symbiotic fungus of Acromyrmex pubescens and phylogeny of Leucoagaricus gongylophorus from leaf-cutting ants. Saudi Journal of Biological Sciences, 2017; 24, 851-856

Boucias DG, Tigano MS, Sosa DR, Glare TR, Inglis PW. Genotypic Properties of the Entomopathogenic Fungus Nomuraea rileyi. Biological Control Journal, 2000; 19: 124-138.

Coates B, Hellmich R, Lewis L. Allelic variation of a Beauveria bassiana (Ascomycota: Hypocreales) minisatellite is independent of host range and geographic origin. Genome, 2002; 45: 125-132.

De A, Bose R, Kumar A, Mozumdar S. Targeted Delivery of Pesticides Using Biodegradable Polymeric Nanoparticles. Springer Briefs in Molecular Science; 2014.

Destéfano RH, Destéfano SAL, Messias CL. Detection of Metarhizium anisopliae var. anisopliae within infected sugarcane borer Diatraea saccharalis (Lepidoptera, Pyralidae) using specific primers. Genetics and Molecular Biology, 2004; 27: 245-252.

Doberski JW, Tribe HT. Isolation of entomogenous fungi elm bark and soil with reference to ecology of Beauveria bassiana and Metarhizium anisopliae. British Mycological Society, Transactions, 1980; 74: 95-100.
Driver F, Milner RJ, Trueman WH. A taxonomic revision of Metarhizium based on a phylogenetic analysis of rDNA sequence data. Mycological Research, 2000; 104: 134-150.

Erler F, Ozgur A. Potential of two entomopathogenic fungi, Beauveria bassiana and Metarhizium anisopliae (Coleoptera: Scarabaeidae), as biological control agents against the June beetle. Journal of Insect Science, 2015; 15: 1-6.

Figueroa L, Varela A, Corredor D. Evaluación de sustratos naturales para la propagación masiva del hongo entomopatógeno Paecilomyces fumosoroseus (Deuteromycotina: Hyphomycetes). Revista de Investigación, 2007; 1(1): 127-131.

Folgarait P, Marfetán J, Cafaro M. Growth and Conidiation Response of Escovopsis weberi (Ascomycota: Hypocreales) Against the Fungal Cultivar of Acromyrmex lundii (Hymenoptera: Formicidae). Environmental Entomology, 2011; 40: 342-349.

Hibbett DS, Ohman A, Glotzer D, Nuhn M, Kirk P, Nilsson RH. Progress in molecular and morphological taxon discovery in Fungi and options for formal classification of environmental sequences. Fungal Biology Reviews, 2011; 25(1): 38-47.

Humber R. Entomopathogenic fungal identification. USDA-ARS Plant Protection Research Unit; 2005.

Humber R. Identification of entomopathogenic fungi. In: Lacey L, Editor. Manual of Techniques in Invertebrate Pathology. 2nd Edition. Academic Press: 2012.

Hyde K, Abd-Elsalam K, Cai L. Morphology: still essential in a molecular world. Mycotaxon, 2010; 114: 439-451.

Izurieta CA. 2000. Estrategia forestal de la provincia de misiones instrumentos para el diseño de políticas. Ministerio de Economía y Producción, República Argentina; 2000.

Kearse M, Moir R, Wilson A, Stones-Havas S, Cheung M, Sturrock $S$ et al. Geneious Basic: an integrated and extendable desktop software platform for the organization and analysis of sequence data. Bioinformatics, 2012; 28: 1647-1649.

Kim K-H, Kabir E, Jahan SA. Exposure to pesticides and the associated human health effects. Science of the Total Environment, 2016; 575: 525-535.

Kindermann J, El-Ayouti Y, Samuels GJ, Kubicek CP. Phylogeny of the Genus Trichoderma Based on Sequence Analysis of the Internal Transcribed Spacer Region 1 of the rDNA Cluster. Fungal Genetics and Biology, 1998; 24: 298- 309.

Kirk PM, Cannon PF, Minter DW, Stalpers JA. Dictionary of the Fungi; 10th ed. CABI; Wallingford: UK: 2008.

Lacey LA, Solter LF. (2012). Initial handling and diagnosis of diseased invertebrates. In: Lacey L, Editor. Manual of Techniques in Invertebrate Pathology. 2nd Edition. Academic Press: 2012.

Lecuona RE. Microorganismos patógenos empleados en el control microbiano de insectos plaga. Mas; Buenos Aires: 1996.

Massoia E, Chebez J, Bosso A. Los mamíferos silvestres de la provincia de Misiones, Argentina. Editorial L.O.L.; Literature of Latin America: 2006.

Pantou MP, Mavridou A, Typas MA. IGS sequence variation, group-I introns and the complete nuclear ribosomal DNA of the entomopathogenic fungus Metarhizium: Excellent tools for isolate 
detection and phylogenetic analysis. Fungal Genetics and Biology, 2003; 38: 159-174.

Paz A, González M, Crawford A. Código de barras dela vida: Introducción y perspectiva. Acta Biológica Colombiana, 2011; 16: 161-176.

Piontelli LE. Manual de microhongos filamentosos communes I. Viña del Mar: Chile: 2015.

Posadas J, Comerio R, Mini J, Lecuona R. A novel dodine-free selective medium based on the use of cetyl trimethyl ammonium bromide (CTAB) to isolate Beauveria bassiana, Metarhizium anisopliae sensu lato and Paecilomyces lilacinus from soil. Mycologia, 2012; 104: 974-980.

Punja ZK, Utkhede RS. Using fungi and yeasts to manage vegetable crop diseases. Trends in Biotechnology, 2003; 21: 400-408.

Rehner SA, Buckley E. A Beauveria phylogeny inferred from nuclear ITS and EF1-a sequences: evidence for cryptic diversification and links to Cordyceps teleomorphs. Mycologia, 2005; 97: 84-98.

Rehner SA, Minnis AM, Sung GH, Luangsa-ard JJ, Devotto L, Humber RA. Phylogeny and systematics of the anamorphic, entomopathogenic genus Beauveria. Mycologia, 2011; 103: 1055-1073.

Samson RA, Evans HC, Latgé JP. Atlas of entomopathogenic fungi. Springer-Verlag Berlin: Heidelberg, 1988.

Sandoval B.C. Manual Técnico Manejo integrado de Enfermedades en cultivos hidropónicos. Facultad de Ciencias Agrarias: Universidad de Talca: 2004.

Schapovaloff ME, Alves LF, Angeli UM, López-Lastra, CC. Ocurrencia natural de hongos entomopatógenos en suelos cultivados con yerba mate (Ilex paraguariensis St. Hil.) en Misiones, Argentina. Revista Argentina de Microbiología, 2015; 47: 138-142.
Schoch CL, Seifert KA, Huhndorf S, Robert V, Spouge JL, Levesque $\mathrm{CA}$, et al. Fungal Barcoding Consortium. Nuclear ribosomal internal transcribed spacer (ITS) region as a universal DNA barcode marker for Fungi. Proceedings of the National Academy of Sciences, 2012; 109: 6241-6246.

Shenoy BD, Jeewon R, Hyde KD. Impact of DNA sequence-data on the taxonomy of anamorphic fungi. Fungal Diversity, 2007; 26: 1-54.

Solé M. Caracterización morfológica y molecular de hongos queratinofílicos: el orden Onygenales. Tesis doctoral. Unidad de Microbiología. Facultad de Medicina y Ciencias de la Salud. Universidad de Rovira y Virgili: 2002.

Tamura K, Stecher G, Peterson D, Filipski A, Kumar S. MEGA6: molecular evolutionary genetics analysis version 6.0. Molecular Biology and Evolution, 2013; 30: 2725-2729.

Teixera R, Faria M. Pequeno manual sobre fungos entomopatogênicos. Embrapa; Brasil: 2010.

Tigano MS, Gomes CM, Sobral BWS. Genetic Variability among Brazilian Isolates of the Entomopathogenic Fungus Metarhizium anisopliae. Journal of Invertebrate Pathology, 1995; 65: 206-210.

Toju H, Tanabe AS, Yamamoto S, Sato H. High-Coverage ITS Primers for the DNA-Based Identification of Ascomycetes and Basidiomycetes in Environmental Samples. PlosOne, 2012; 7:e40863.

Weber E. Densidad básica de madera de Pinus taeda L. Marion de diferentes edades, Misiones, Argentina. Floresta, 2005; 35: 487-494.

White TJ, Bruns TD, Lee SB, Taylor JW. Analysis of phylogenetic relationships by amplification and direct sequencing of ribosomal genes. In: Innis MA, Gelfand DH, Sninsky JJ, White TJ, Editors. PCR Protocols; Academic Press; New York: 1990. 